\title{
CONSUMER SENTIMENT AND INDONESIA'S STOCK RETURNS
}

\author{
Deepa Bannigidadmath
}

School of Business and Law, Edith Cowan University, Australia. Email: d.bannigidadmath@ecu.edu.au

\begin{abstract}
This paper examines whether consumer sentiment predicts the excess returns of the aggregate market and nine industries from the Indonesia equity market. We discover evidence of predictability for three industries; however, the magnitude of predictability are heterogeneous. Some sectors are predictable during expansions, whereas others are only predictable during recessions. There is no evidence of the reversal of the impact of consumer sentiment on stock returns. We conduct several robustness tests that include (i) estimating a predictive regression model with a feasible quasi-generalized least squares-based estimator and (ii) accounting for structural breaks. These tests confirm the baseline results.
\end{abstract}

Keywords: Stock returns; Consumer sentiment; Predictability; Business cycle.

JEL Classifications: G12; G17.

Article history:

Received : July 4, 2019

Revised : November 29, 2019

Accepted : December 20, 2020

Available online : January 31, 2020

https://doi.org/10.21098/bemp.23vi0i.1194 


\section{INTRODUCTION}

This study examines whether consumer sentiment predicts Indonesia's stock returns. A number of studies suggest that consumer sentiment is highly correlated with real economic activity and that it contains vital information about the future and current states of the economy (Romer, 1990; Throop, 1992; Ludvigson, 2004; Chen, 2011). Few other studies examine the relation between stock returns and changes in consumer sentiment (Lee et al., 2002; Fisher and Statman, 2003; Jansen and Nahuis, 2003; Baker and Wurglar, 2006; Lemmon and Portniaguina, 2006; Schmeling, 2009). The evidence from these studies indicates that consumer sentiment predicts stock returns.

This study contributes to the literature in two distinct ways. First, most studies examining the relation between consumer sentiment and stock returns focus on the aggregate market index and ignore the heterogeneity among industries. Recent studies on industry return predictability (Narayan and Bannigidadmath, 2015; Bannigidadmath and Narayan, 2016; Phan et al., 2019) indicate that predictability is industry specific. We therefore explore this angle by considering nine industries in our analysis. Second, most studies on predictability are from developed markets (for a review of the literature, see Rapach et al., 2010). The literature is scarce when it comes to emerging markets (Narayan et al., 2015, 2016b; Phan et al., 2019). ${ }^{1}$ Only recently, Phan et al. (2019) have examined the predictability of Indonesia's industry returns, using macroeconomic variables as predictors. We contribute to this literature by investigating whether changes in consumer sentiment predict Indonesia's industry returns differently.

The empirical analysis involves the following steps. First, we estimate the time series regression models using a change in consumer sentiment as a predictor and excess returns as the dependent variable. Second, we account for Indonesia's business cycles and examine whether any differences in predictability exist between expansions and recessions. Third, we conduct a number of robustness tests to ascertain our baseline results. This involves using Westerlund and Narayan's (2012, 2015) feasible generalized least squares-based estimator for predictability tests. In additional robustness tests, we re-estimate our main results by accounting for structural breaks identified using Bai and Perron's (2003) sequential SupF statistic.

This study finds the following results. First, this study provides fresh evidence on the link between consumer sentiment and the Indonesian equity market. We find evidence of predictability for three industries: consumer goods, consumer services, and oil and gas. This indicates the importance of considering an industry analysis rather than focusing only on the aggregate market. Second, we find variations in the magnitude of predictability across sectors. The magnitude of predictability is highest for the oil and gas sector and the lowest for the consumer goods sector. This result is consistent with the gradual diffusion hypothesis of Hong and Stein (1999) and Hou (2007), which states that information diffusion is slow in certain sectors, leading to differences in predictability among industries.

\footnotetext{
Debata et al. (2018) examine the relation between emerging stock market liquidity and investor sentiment by considering an analysis of Indonesian aggregate market data. Our paper differs from theirs, because ours focuses on excess return predictability.
} 
Third, we find that the impact of consumer sentiment on returns persists since there is no evidence of reversal of the effect of consumer sentiment on returns. Fourth, we test for predictability considering Indonesia's business cycle and arrive at similar results. A range of robustness tests reveals that the main findings still hold.

The remainder of the paper is organized as follows. Section II discusses the data and the empirical framework. The main findings and robustness tests are presented in Section III. Section IV draws our concluding remarks.

\section{DATA AND METHODOLOGY}

This study uses monthly data on Indonesia's stock index returns and the consumer sentiment index obtained from Datastream and Federal Reserve Economic Data (FRED). The sample period of the data is from March 2003 to April 2019. The monthly prices of the aggregate market index and nine industries (basic materials, consumer goods, consumer services, financials, health care, industrials, oil and gas, technology, and telecommunications) are downloaded from Datastream. The data for the utility sector start in July 2004. We therefore exclude the utility sector from our analysis. The consumer sentiment index and risk-free rate for Indonesia are downloaded from FRED. ${ }^{2}$ Indonesia's three-month interbank rate is used as a proxy for the risk-free rate to compute excess returns.

The empirical model is motivated by the recent literature that investigates the impact of textual analysis-based news sentiment on stock returns (Garcia, 2013; Narayan and Bannigidadmath, 2017). The approach involves estimating the time series regression model with excess returns of the aggregate market or industry as the dependent variable:

$$
R_{t}=\alpha+\beta_{j} \sum_{j=1}^{5} \text { Sentiment }_{t-j}+\delta_{j} \sum_{j=1}^{5} R_{t-j}+\theta_{j} \sum_{j=1}^{5} R_{t-j}^{2}+\varepsilon_{t}
$$

where $R_{t}$ represents the excess returns for the aggregate market and the nine industries and Sentiment refers to change in the consumer sentiment index. Lagged industry returns are included to capture serial correlation. The volatility of the returns is controlled for by using squared returns. A Newey-West (1987) procedure is used to correct standard errors for autocorrelation and heteroskedasticity, using a maximum of 12 lags.

In additional tests, we ascertain the robustness of our findings by using Westerlund and Narayan's $(2012,2015)$ bivariate predictive regression model. ${ }^{3}$ The main advantage of this model is that it addresses the issues of persistency, endogeneity, and heteroskedasticity prevalent in the data. It could be argued that Equation (1) suffers from an endogeneity problem, and, therefore, the results

2 FRED can be accessed at https://fred.stlouisfed.org/categories/3226

3 This model has been widely used in predicting stock returns. For a detailed discussion on this model, see Narayan et al. (2014), Narayan and Gupta (2015), Narayan and Sharma (2015), Narayan et al. (2015), Phan et al. (2015), Narayan et al. (2016a), Devpura et al. (2018), Narayan et al. (2017), Phan et al. (2018), and Narayan et al. (2018). 
could be biased. We address this issue by using the feasible quasi-generalized least squares based estimator (FQGLS) for predictability tests.

\section{EMPIRICAL RESULTS}

A. Preliminary Analysis

A plot of the consumer sentiment index is presented in Figure 1. The index dropped to a low of 47 points during the global financial crisis period. The descriptive statistics of the excess returns for the aggregate market and nine industries are presented in Table 1. The mean return of the market in excess of the risk-free rate is $0.397 \%$. The mean returns of the industries vary from $-1.917 \%$ for the oil and gas sector to $0.354 \%$ for the financial sector. The returns of the oil and gas sector are the most volatile, and those of the telecommunications sector the least volatile.

Figure 1.

A Plot of Indonesia's Consumer Sentiment Index

This figure shows the plot of the time series consumer sentiment index for Indonesia. Monthly data is extracted from the Federal Reserve Economic Data for the sample period 2003M03-2019M04.

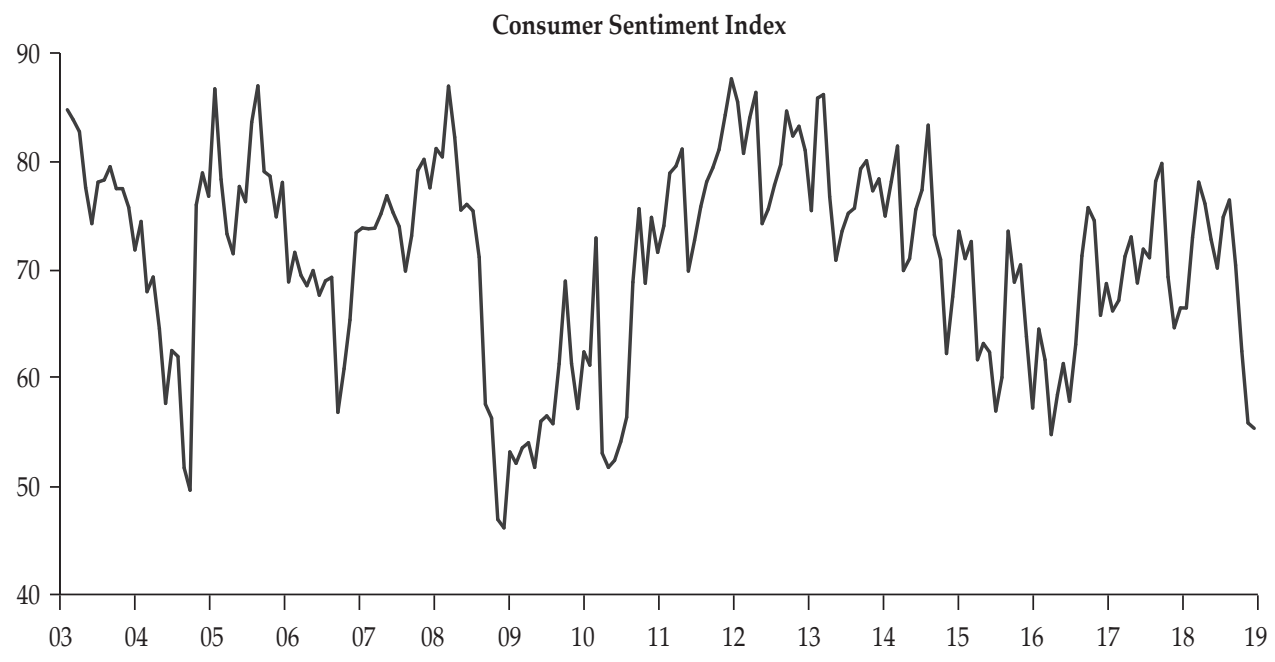

The AR(1) coefficient and the autocorrelations of squared returns are reported in columns (6) and (7) of Table 1. The AR(1) coefficient is close to one for all the variables, indicating that the returns are highly persistent. The autocorrelation of the squared variable suggests the presence of ARCH effects. The statistics reported in column (7) suggest the strong presence of ARCH for the market and five sectors. Lastly, the unconditional correlations between changes in consumer sentiment and excess returns are reported in the last column. The $p$-values reported in parentheses indicate that changes in consumer sentiment are positively correlated with basic materials and the consumer services sectors. The magnitude of the correlation coefficient varies between industries, suggesting that consumer sentiment could predict industry returns differently. 
Table 1.

\section{Descriptive Statistics of the Aggregate Market and Industries}

The table reports the descriptive statistics of excess returns for the aggregate market and nine industries considered in the empirical analysis. The data is monthly and covers the sample period 2003M03-2019M04. The statistics - mean, standard deviation, skewness, kurtosis, the first-order autoregressive coefficient, and the autocorrelation of returns are reported in the table. The $p$-value corresponding to the Ljung-Box Q-statistic that tests the null hypothesis of no autocorrelation is reported in parenthesis. The unconditional correlation of excess returns with the change in consumer sentiment index is reported in the last column of the table.

\begin{tabular}{lccccccc}
\hline & Mean & $\begin{array}{c}\text { Std. } \\
\text { dev }\end{array}$ & Skew. & Kurt. & $\begin{array}{c}\text { AR(1) } \\
\text { coefficient }\end{array}$ & $\begin{array}{c}\text { AC } \\
\text { (Q-stat) }\end{array}$ & $\begin{array}{c}\text { Unconditional } \\
\text { Correlation }\end{array}$ \\
\hline Aggregate Market & 0.397 & 5.910 & -1.898 & 14.552 & 0.993 & $0.178(0.025)$ & $0.076(0.342)$ \\
Basic Materials & -0.829 & 13.121 & -1.138 & 9.002 & 0.971 & $0.583(0.000)$ & $0.142(0.076)$ \\
Consumer Goods & 0.171 & 9.126 & -2.149 & 18.189 & 0.976 & $0.092(0.244)$ & $0.041(0.613)$ \\
Consumer Services & -0.584 & 10.644 & -0.331 & 5.178 & 0.975 & $0.234(0.003)$ & $0.149(0.063)$ \\
Financials & 0.354 & 8.944 & -0.809 & 7.203 & 0.983 & $0.144(0.068)$ & $0.052(0.516)$ \\
Health Care & 0.129 & 10.651 & -0.626 & 11.947 & 0.984 & $0.014(0.856)$ & $0.018(0.821)$ \\
Industrials & -0.147 & 10.618 & -2.495 & 22.505 & 0.964 & $0.073(0.357)$ & $0.106(0.188)$ \\
Oil and Gas & -1.917 & 14.282 & -0.071 & 5.930 & 0.965 & $0.327(0.000)$ & $0.081(0.313)$ \\
Technology & -0.143 & 8.618 & -1.743 & 14.575 & 0.951 & $0.250(0.002)$ & $0.088(0.274)$ \\
Telecommunications & -0.412 & 7.780 & -0.603 & 7.343 & 0.925 & $0.078(0.325)$ & $-0.033(0.680)$ \\
\hline
\end{tabular}

\section{B. Evidence from Time Series Regression Models}

The results for the aggregate market and nine industries with changes in consumer sentiment as the predictor are reported in Table 2. The last column reports the results for the null hypothesis test $\sum_{j=2}^{5} \beta_{j}=0$. The sign and statistical significance of the coefficient indicate whether the impact of the consumer sentiment on industry returns at lag $t-1$ is permanent or temporary.

Table 2.

\section{Impact of the Change in Consumer Sentiment for the Full-sample Period}

This table reports the results of excess return predictability based on the change in consumer sentiment index. The table reports the coefficients $\beta$ from the model: $R_{t}=\alpha+\beta \sum_{j=1}^{5} S_{\text {entiment }}+j+\delta_{j} \sum_{j=1}^{5} R_{t-j}+\theta_{j} \sum_{j=1}^{5} R_{t-j}^{2}+\varepsilon_{t}$. Here, Sentiment refers to the change in the consumer sentiment index. $R_{t}$ represents the excess returns for the aggregate market and the nine industries. The data is monthly and covers the sample period 2003M03-2019M04. The $t$-statistic testing the null hypothesis that $\beta=0$ is based on standard errors corrected for heteroskedasticity and autocorrelation of up to 12 lags using the Newey-West (1987) procedure. The Wald test results, testing the null hypothesis that $\sum_{j=2}^{5} \beta_{j}=0$ are reported in the last column. The $F$-statistic is reported in square brackets.

\begin{tabular}{lccccccc}
\hline & $\boldsymbol{\beta}_{1}$ & $\boldsymbol{\beta}_{2}$ & $\boldsymbol{\beta}_{\mathbf{3}}$ & $\boldsymbol{\beta}_{4}$ & $\boldsymbol{\beta}_{\mathbf{5}}$ & $\boldsymbol{R}^{2}$ & $\sum_{j=2}^{5} \boldsymbol{\beta}_{\boldsymbol{j}}=\mathbf{0}$ \\
\hline Aggregate Market & 0.008 & 0.016 & -0.042 & 0.031 & -0.096 & \multirow{2}{*}{0.022} & -0.091 \\
& $(0.198)$ & $(0.339)$ & $(-1.140)$ & $(0.777)$ & $(-1.509)$ & & {$[0.827]$} \\
Basic Materials & 0.066 & 0.187 & -0.088 & 0.13 & -0.246 & 0.009 & -0.019 \\
& $(0.524)$ & $(1.434)$ & $(-1.278)$ & $(0.787)$ & $(-1.626)$ & & {$[0.007]$} \\
Consumer Goods & 0.101 & 0.048 & -0.042 & 0.099 & -0.17 & 0.049 & -0.065 \\
& $(2.086)$ & $(0.775)$ & $(-0.911)$ & $(1.676)$ & $(-1.479)$ & & {$[0.147]$} \\
Consumer Services & 0.184 & -0.004 & 0.084 & 0.055 & 0.014 & 0.022 & 0.148 \\
& $(2.167)$ & $(-0.061)$ & $(0.993)$ & $(0.620)$ & $(0.116)$ & & {$[0.802]$} \\
Financials & 0.006 & 0.046 & -0.069 & 0.099 & -0.116 & 0.024 & -0.040 \\
& $(0.088)$ & $(0.719)$ & $(-0.799)$ & $(1.022)$ & $(-1.106)$ & & {$[0.031]$} \\
Health Care & -0.009 & 0.046 & -0.149 & 0.129 & -0.228 & 0.049 & -0.202 \\
& $(-0.176)$ & $(0.636)$ & $(-2.654)$ & $(3.025)$ & $(-1.505)$ & & {$[0.714]$} \\
Industrials & -0.046 & -0.049 & -0.126 & 0.021 & -0.132 & 0.007 & -0.287 \\
& $(-0.580)$ & $(-0.629)$ & $(-1.918)$ & $(0.288)$ & $(-1.133)$ & & {$[3.054]$} \\
Oil and Gas & 0.313 & 0.086 & -0.076 & -0.055 & 0.173 & 0.051 & 0.128 \\
& $(2.603)$ & $(0.965)$ & $(-0.442)$ & $(-0.344)$ & $(1.077)$ & & {$[0.092]$} \\
\hline
\end{tabular}


Table 2.

Impact of the Change in Consumer Sentiment for the Full-sample Period (Continued)

\begin{tabular}{lccccccc}
\hline & $\boldsymbol{\beta}_{\mathbf{1}}$ & $\boldsymbol{\beta}_{2}$ & $\boldsymbol{\beta}_{\mathbf{3}}$ & $\boldsymbol{\beta}_{4}$ & $\boldsymbol{\beta}_{5}$ & \multirow{2}{*}{$\boldsymbol{R}^{2}$} & $\sum_{j=2}^{5} \boldsymbol{\beta}_{j}=\mathbf{0}$ \\
\hline Technology & 0.058 & 0.036 & -0.062 & 0.076 & -0.128 & \multirow{2}{*}{0.030} & -0.078 \\
& $(1.110)$ & $(0.651)$ & $(-1.175)$ & $(1.416)$ & $(-1.219)$ & & {$[0.243]$} \\
Telecommunications & -0.053 & 0.016 & -0.067 & 0.067 & -0.084 & \multirow{2}{*}{0.017} & -0.068 \\
& $(-0.822)$ & $(0.297)$ & $(-1.291)$ & $(1.289)$ & $(-0.838)$ & {$[0.230]$} \\
\hline
\end{tabular}

The results have three important features. First, there is no evidence of predictability for the aggregate market. However, we find that one-period-lagged changes in consumer sentiment positively predict returns for three out of nine industries (oil and gas, consumer goods, and consumer services). Second, the magnitude of predictability is highest for the oil and gas sector and the lowest for the consumer goods sector. This difference in predictability among industries is consistent with the literature on industry return predictability (Narayan and Bannigidadmath, 2015; Phan et al., 2019). These studies document that the predictability of industry returns using financial ratios and macroeconomic variables differs among industries. The underlying economic intuition is that information diffusion is slow in certain sectors, leading to differences in return predictability across industries (e.g., Hong and Stein, 1999; Hou, 2007). Third, for industries with evidence of predictability, we examine whether the Wald test results in the last column of Table 2 are statistically significant. ${ }^{4}$ We find that the sum of lagged coefficients is not statistically significant, indicating a persistent impact of consumer sentiment on industry returns.

\section{Effect of Consumer Sentiment along the Business Cycle}

A number of studies document higher return predictability during recessions than during expansions (Rapach et al., 2010; Narayan and Bannigidadmath, 2015). Fama and French (1989) contend that the degree of risk aversion increases during recessions, inducing investors to demand higher returns during recessions. This leads to significant differences in return predictability across business cycles. We therefore use the following regression model to test differences in return predictability during the expansions and recessions.

$$
\begin{aligned}
& R_{t}=\alpha+(1-b c)\left(\beta_{j} \sum_{j=1}^{5} \text { Sentiment }_{t-j}+\delta_{j} \sum_{j=1}^{5} R_{t-j}+\theta_{j} \sum_{j=1}^{5} R_{t-j}^{2}\right) \\
&+b c\left(\gamma_{j} \sum_{j=1}^{5} \text { Sentiment }_{t-j}+\psi_{j} \sum_{j=1}^{5} R_{t-j}+\eta_{j} \sum_{j=1}^{12} R_{t-j}^{2}\right)+\varepsilon_{t}
\end{aligned}
$$

where $b c$ is a dummy variable with a value of one during recessions and zero during expansions. We consider the OECD business cycle data for Indonesia downloaded from FRED.

4 The Wald test results capture the sign and statistical significance of coefficients from lag 2 to lag 5 . If the sum of coefficients from lag 2 to lag 5 is of opposite sign to the lag 1 coefficient and is statistically significant, then there is return reversal and the effect of consumer sentiment does not, therefore, persist. 


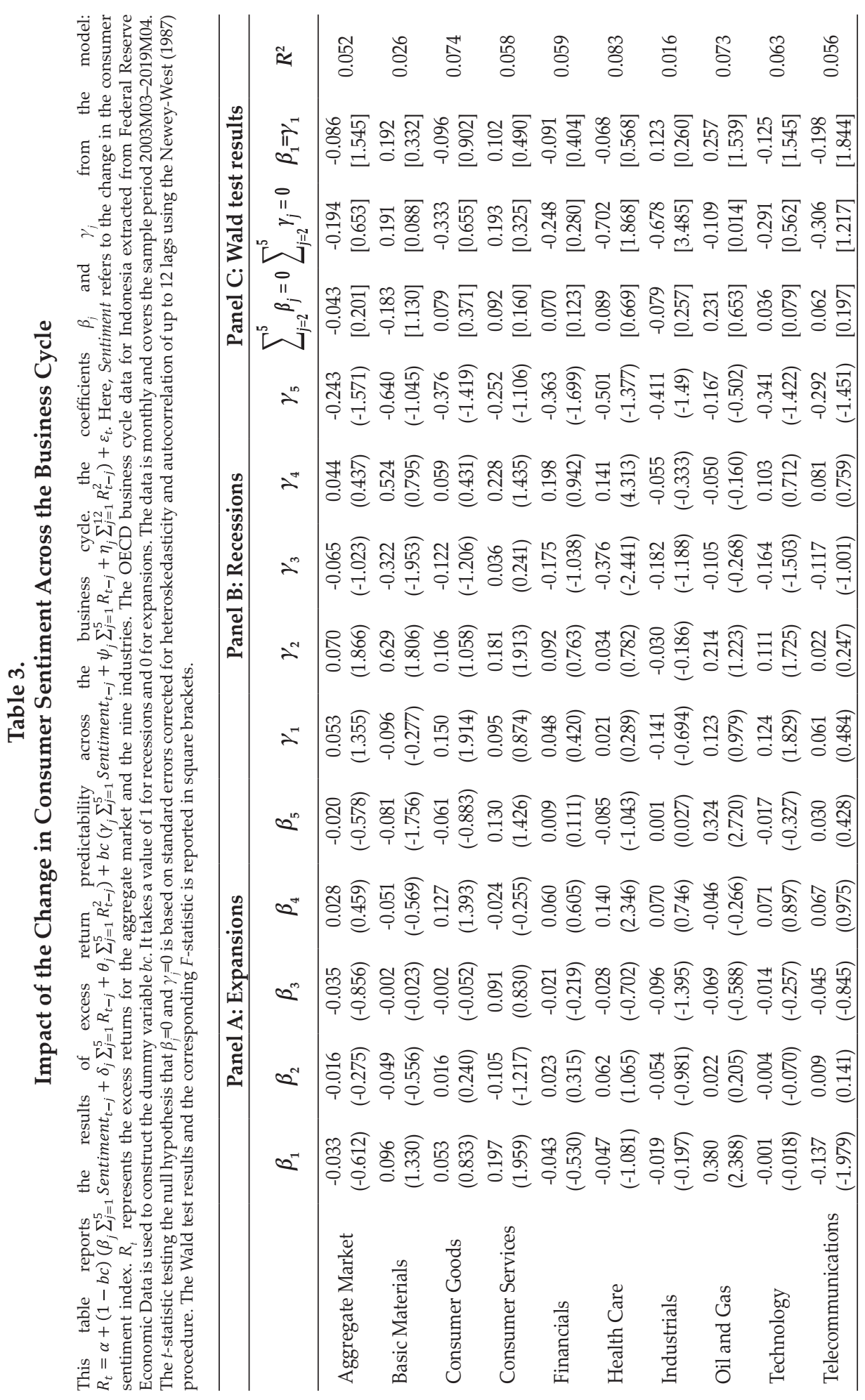


The results of the above regression model are reported in Table 3. Panel A (B) reports the coefficients and corresponding t-statistics during expansions (recessions). Panel $\mathrm{C}$ reports the Wald test results. We find that one-periodlagged changes in consumer sentiment predict returns for three industries (oil and gas, consumer services, and telecommunications) during expansions and two industries (consumer goods and technology) during recessions. Oil and gas, consumer services, and consumer goods are also the industries that are predictable from our main results. The Wald test results in the first two columns of Panel $\mathrm{C}$ indicate no reversal of the impact of consumer sentiment on industry returns. The Wald test results in the last column show whether the one-period-lagged coefficient of change in consumer sentiment during expansions is equal to the one-period-lagged coefficient of change in consumer sentiment during a recession. There is no evidence of any significant differences in return predictability across business cycles. However, the results indicate that certain sectors are predictable only during expansions, and other sectors only during recessions. These results are consistent with those of Kadan et al. (2012), who argue that macroeconomic cycles do not affect all sectors evenly and, therefore, industry return predictability reveals additional information that cannot be captured from aggregate market return predictability.

\section{Robustness Tests}

A number of robustness tests are conducted to confirm the baseline results. It could be argued that the model represented in Equation (1) suffers from an endogeneity problem. We therefore undertake an analysis by using Westerlund and Narayan's (2012, 2015) FQGLS-based estimator for predictability tests. This model takes care of the persistency, heteroskedasticity, and endogeneity issues present in the data. The results in Table 4 indicate evidence of predictability for three industries: consumer goods, consumer services, and the oil and gas sectors. The magnitude of predictability is highest for the oil and gas sector, and lowest for the consumer goods sector. These results corroborate our main findings.

\section{Table 4.}

\section{Predictability Tests using the FQGLS Estimator}

This table reports the results of excess return predictability by using a bi-variate predictive regression model with a change in consumer sentiment as the predictor of excess returns for the aggregate market and nine industries. The Westerlund and Naryan $(2012,2015)$ FQGLS estimator is used to make the inference. The data is monthly and covers the sample period 2003M03-2019M04.

\begin{tabular}{lcc}
\hline & Coefficient & $t$-statistic \\
\hline Aggregate Market & 0.024 & 0.461 \\
Basic Materials & 0.099 & 0.375 \\
Consumer Goods & 0.127 & 1.665 \\
Consumer Services & 0.179 & 2.017 \\
Financials & 0.029 & 0.371 \\
Health Care & 0.040 & 0.427 \\
Industrials & -0.003 & -0.026 \\
\hline
\end{tabular}


Table 4.

Predictability Tests using the FQGLS Estimator (Continued)

\begin{tabular}{lcc}
\hline & Coefficient & $\boldsymbol{t}$-statistic \\
\hline Oil and Gas & 0.261 & 2.301 \\
Technology & 0.075 & 1.073 \\
Telecommunications & -0.030 & -0.427 \\
\hline
\end{tabular}

In additional robustness tests, we run our main model, presented in Equation (1), after accounting for structural breaks. The literature provides substantial evidence to support the presence of structural instabilities in the financial data (see Devpura et al., 2019, and references therein). The source of such instabilities could be the changes in policy leading to major industry and/or macroeconomic shocks. Therefore, there could be differences in predictability before or after a structural break. In our empirical tests, we allow for a maximum of one structural break in excess returns, using Bai and Perron's (2003) sequential SupF statistic. ${ }^{5}$ Table 5 presents the results along with the structural break dates. We find evidence of predictability for the consumer services sector before the structural break occurs. The returns of the oil and gas, consumer goods, and technology sectors are predictable after the occurrence of a structural break, whereas the returns of the consumer services sector are predictable before the occurrence of a structural break. The baseline results indicate evidence of predictability for the oil and gas, consumer services, and consumer goods sectors. The robustness tests largely corroborate our baseline results.

Table 5.

\section{Impact of the Change in Consumer Sentiment by Accounting for Structural Breaks}

This table reports the results of excess return predictability by accounting for structural breaks obtained using Bai and Perron (2003) test. The following regression model is estimated before and after the structural break: $R_{t}=\alpha+\beta_{j} \sum_{j=1}^{5}$ Sentiment $_{t-j}+\delta_{j} \sum_{j=1}^{5} R_{t-j}+\theta_{j} \sum_{j=1}^{5} R_{t-j}^{2}+\varepsilon_{t}$. Here, Sentiment refers to the change in the consumer sentiment index. $R_{t}$ represents the excess returns for the aggregate market and the nine industries. The table reports the structural break dates, the one-period lagged coefficient of the change in consumer sentiment index, and the $R$-squared from the model. The data is monthly and covers the sample period 2003M03-2019M04. The $t$-statistic testing the null hypothesis that $\beta=0$ is based on standard errors corrected for heteroskedasticity and autocorrelation of up to 12 lags using the Newey-West (1987) procedure.

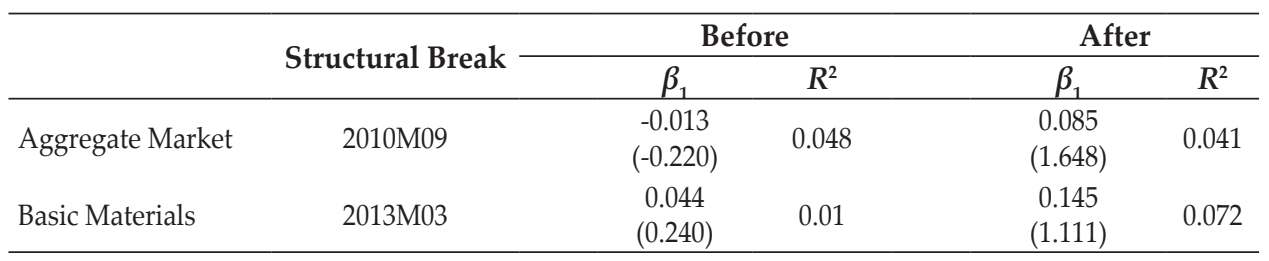

5 Bai and Perron's (2003) test does allow for multiple structural breaks in the sample. However, we consider a maximum of one break, due to the very short sample period. The intention here is to identify the break dates, to analyze subsample predictability. Allowing for more than one break will result in multiple subsamples with very short periods, such that the predictability test results are no longer meaningful. Narayan and Popp (2010) two structural break test would also have been ideal (see Narayan and Popp, 2013). Narayan (2019) follows a similar procedure to analyze the robustness of stock return predictability by using oil price news as a predictor. 
Table 5.

Impact of the Change in Consumer Sentiment by Accounting for Structural Breaks (Continued)

\begin{tabular}{|c|c|c|c|c|c|}
\hline & \multirow{2}{*}{ Structural Break } & \multicolumn{2}{|c|}{ Before } & \multicolumn{2}{|c|}{ After } \\
\hline & & $\beta_{1}$ & $R^{2}$ & $\beta_{1}$ & $R^{2}$ \\
\hline Consumer Goods & 2010M03 & $\begin{array}{c}0.106 \\
(0.882)\end{array}$ & 0.094 & $\begin{array}{c}0.157 \\
(2.170)\end{array}$ & 0.107 \\
\hline Consumer Services & 2010M12 & $\begin{array}{c}0.251 \\
(2.259)\end{array}$ & 0.043 & $\begin{array}{c}0.065 \\
(0.517)\end{array}$ & 0.037 \\
\hline Financials & 2010M04 & $\begin{array}{c}-0.068 \\
(-0.530)\end{array}$ & 0.055 & $\begin{array}{c}0.116 \\
(1.588)\end{array}$ & 0.092 \\
\hline Health Care & 2010M10 & $\begin{array}{c}-0.032 \\
(-0.233)\end{array}$ & 0.073 & $\begin{array}{c}0.056 \\
(0.423)\end{array}$ & 0.040 \\
\hline Industrials & 2009M09 & $\begin{array}{c}-0.187 \\
(-0.661)\end{array}$ & 0.010 & $\begin{array}{c}0.106 \\
(1.182)\end{array}$ & 0.048 \\
\hline Oil and Gas & 2008M10 & $\begin{array}{c}0.140 \\
(0.555)\end{array}$ & 0.234 & $\begin{array}{c}0.374 \\
(2.660)\end{array}$ & 0.054 \\
\hline Technology & 2009M12 & $\begin{array}{c}0.024 \\
(0.211)\end{array}$ & 0.055 & $\begin{array}{c}0.119 \\
(1.911)\end{array}$ & 0.090 \\
\hline Telecommunications & 2006M03 & $\begin{array}{c}-0.185 \\
(-1.300)\end{array}$ & 0.072 & $\begin{array}{c}-0.018 \\
(-0.253)\end{array}$ & 0.026 \\
\hline
\end{tabular}

\section{E. Implications}

The results have two important implications. First, investors can utilize an FQGLS-based estimator to devise a trading strategy based on changes in the consumer sentiment index. Our main results suggest that only specific sectors are predictable. This finding will enable investors to focus on those particular industries and enhance their portfolio performance. Second, our analysis reveals that, in Indonesia, oil and gas is the most predictable sector. This has been the most volatile industry, driven by both domestic and global factors. Although Indonesia has significant energy resources, including oil, it has been a net exporter of oil for the larger part of our sample, since 2004. This is due to the increase in oil consumption relative to oil production. The Indonesian government is working on changes in regulations to boost this sector. Our results indicate that consumer sentiment predicts oil and gas sector returns. Therefore, it is vital for policymakers to take into account the impact of any changes in regulations on consumer sentiment and the oil and gas sector returns.

\section{CONCLUSION}

This paper investigates whether Indonesia's aggregate market and nine industry returns can be predicted by the consumer sentiment index. We use monthly data for a sample period from March 2003 to April 2019. Our empirical approach involves estimating time series regression models, using a change in consumer sentiment as a predictor and excess returns as the dependent variable. First, our results indicate that changes in consumer sentiment do not predict excess returns in the Indonesia market index; however, we find that one-period-lagged changes 
in consumer sentiment positively predict returns for three sectors, namely, oil and gas, consumer goods, and consumer services. This result suggests that it vital to consider industry analysis rather than focusing only on the aggregate market. Second, the findings indicate that predictability is heterogeneous, in that the magnitude of predictability is highest for the oil and gas sector and lowest for the consumer goods sector. This difference in predictability among industries is consistent with the recent literature, which documents that the predictability of industry returns using financial ratios and macroeconomic variables differs among industries. Lastly, for industries with evidence of predictability, we test for reversal of the impact of consumer sentiment on industry returns. We find that the impact of consumer sentiment on industry returns persists and is not temporary. A range of robustness tests reveals that the main findings hold.

\section{REFERENCES}

Bai, J. and Perron, P. (2003). Computation and Analysis of Multiple Structural Change Models. Journal of Applied Econometrics, 18, 1-22.

Baker, M. and Wurgler, J. (2006). Investor Sentiment and the Cross-Section of Stock Returns. Journal of Finance, 61, 1645-1680.

Bannigidadmath, D. and Narayan, P.K. (2016). Stock Return Predictability and Determinants of Predictability and Profits. Emerging Markets Review, 26, 153-173.

Chen, S.S. (2011). Lack of Consumer Confidence and Stock Returns. Journal of Empirical Finance, 18, 225-236.

Debata, B., Dash, S.R. and Mahakud, J. (2018). Investor Sentiment and Emerging Stock Market Liquidity. Finance Research Letters, 26, 15-31.

Devpura, N., Narayan, P.K. and Sharma, S.S. (2018). Is stock return predictability time-varying? Journal of International Financial Markets, Institutions and Money, $52,152-172$.

Devpura, N., Narayan, P.K. and Sharma, S.S., (2019). Structural Instability and Predictability. Journal of International Financial Markets, Institutions and Money, 63.

Fama, E. and French, K. (1989). Business Conditions and Expected Return on Stocks and Bonds. Journal of Financial Economics, 25, 23-49.

Fisher, K.L. and Statman, M. (2003). Consumer Confidence and Stock Returns. Journal of Portfolio Management, 30, 115-127.

García, D. 2013. Sentiment During Recession. Journal of Finance, 68, 1267-1300.

Hong, H. and Stein, J.C. (1999). A Unified Theory of Underreaction, Momentum Trading, and Overreaction in Asset Markets. Journal of Finance, 54, 2143-2184

Hou, K. 2007. Industry Information Diffusion and The Lead-Lag Effect in Stock Returns. Review of Financial Studies, 20, 1113-1138.

Jansen, W.J. and Nahuis, N.J. (2003). The Stock Market and Consumer Confidence: European evidence. Economics Letters, 79, 89-98.

Kadan, O., Madureira, L., Wang, R. and Zach, T. (2012). Analysts' Industry Expertise. Journal of Accounting and Economics, 54, 95-120.

Lee, W.Y., Jiang, C.X. and Indro, D.C. (2002). Stock Market Volatility, Excess Returns, and the Role of Investor Sentiment. Journal of Banking and Finance, 26, 2277-2299. 
Lemmon, M. and Portniaguina, E. (2006). Consumer Confidence and Asset Prices: Some Empirical Evidence. Review of Financial Studies, 19, 1499-1529.

Ludvigson, S.C. (2004). Consumer Confidence and Consumer Spending. Journal of Economic perspectives, 18, 29-50.

Narayan, P.K. and Bannigidadmath, D. (2015). Are Indian Stock Returns Predictable? Journal of Banking and Finance, 58, 506-531.

Narayan, P.K. and Bannigidadmath, D. (2017). Does Financial News Predict Stock Returns? New Evidence from Islamic and non-Islamic Stocks. Pacific-Basin Finance Journal, 42, 24-45.

Narayan, P.K. and Gupta, R. (2015). Has Oil Price Predicted Stock Returns for Over a Century? Energy Economics, 48, 18-23.

Narayan, P.K. and Sharma, S. (2015). Is Carbon Emissions Trading Profitable? Economic Modelling, 47, 84-92.

Narayan, P.K., Phan, D.H.B. and Narayan, S. (2018). Technology-Investing Countries and Stock Return Predictability. Emerging Markets Review, 36, 159179.

Narayan, P.K., Phan, D.H.B., Narayan, S. and Bannigidadmath, D. (2017). Is There a Financial News Risk Premium in Islamic Stocks? Pacific-Basin Finance Journal, 42, 158-170.

Narayan, P.K., Phan, D.H.B., Sharma, S.S. and Westerlund, J. (2016). Are Islamic Stock Returns Predictable? A Global Perspective. Pacific-Basin Finance Journal, 40, 210- 233.

Narayan, P.K., Phan, D.H.B, Thuraisamy, K. and Westerlund, J. (2016). Price Discovery and Asset Pricing. Pacific-Basin Finance Journal, 40, 224-235.

Narayan, P.K., Sharma, S.S., and Thuraisamy, K.S. (2015). Can Governance Quality Predict Stock Market Returns? New Global Evidence. Pacific-Basin Finance Journal, 35, 367-380.

Narayan, P.K, Sharma, S.S., Poon, W. and Westerlund, J. (2014). Do Oil Prices Predict Economic Growth? New Global Evidence. Energy Economics, 41, 137146.

Narayan, P.K. (2019). Can Stale Oil Price News Predict Stock Returns? Energy Economics, 83, 430-444.

Narayan, P. K., and Popp, S. (2010). A New Unit Root Test with Two Structural Breaks in Level and Slope at Unknown Time. Journal of Applied Statistics, 37, 1425-1438.

Narayan, P. K., and Popp, S. (2013). Size and Power Properties of Structural Break Unit Root Tests. Applied Economics, 45, 721-728.

Newey, W., and West, K. (1987). A Simple, Positive Fefinite, Heteroskedastic and Autocorrelation Consistent Covariance Matrix. Econometrica, 55, 703-708.

Phan, D.H.B., Nguyen, T.T.N. and Nguyen, D.T. (2019). A Study of Indonesia's Stock Market: How Predictable Is It?. Bulletin of Monetary Economics and Banking, 21, 465-476.

Phan, D.H.B., Sharma, S.S., and Narayan, P. K. (2015). Stock Return Forecasting: Some New Evidence. International Review of Financial Analysis, 40, 38-51.

Phan, D.H.B., Sharma, S.S., and Tran, V.T. (2018). Can Economic Policy Uncertainty Predict Stock Returns? Global Evidence. Journal of International Financial Markets, Institutions and Money, 55, 134-150. 
Rapach, D.E., Strauss, J.K., and Zhou, G., (2010). Out-of-sample equity premium prediction: Combination forecasts and links to the real economy. Review of Financial Studies, 23, 821-862.

Romer, C.D. (1990). The great crash and the onset of the great depression. The Quarterly Journal of Economics, 105, 597-624.

Schmeling, M. (2009). Investor sentiment and stock returns: Some international evidence. Journal of Empirical Finance, 16, 394-408.

Throop, A.W. (1992). Consumer sentiment: Its causes and effects. Federal Reserve Bank of San Francisco Economic Review, 1, 35-59.

Westerlund, J., and Narayan, P.K. (2012). Does the choice of estimator matter when forecasting returns?. Journal of Banking E Finance, 36, 2632-2640.

Westerlund, J., and Narayan, P.K. (2015). Testing for predictability in conditionally heteroskedastic stock returns. Journal of Financial Econometrics, 13, 342-375. 
This page is intentionally left blank 